\begin{tabular}{|c|c|c|}
\hline $\begin{array}{l}\text { EXCELLENT } \\
\text { PUBLISHERS } \\
\end{array}$ & $\begin{array}{l}\text { International Journal of Current Research } \\
\text { and Academic Review } \\
\text { ISSN: 2347-3215 (Online):,: Volume } 5 \text { :,; Number } 10 \text { (October-2017) } \\
\text { Journal homepage: http://www.ijcrar.com }\end{array}$ & 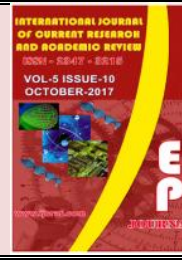 \\
\hline
\end{tabular}

doi: https://doi.org/10.20546/ijcrar.2017.510.009

\title{
Health Problems among Elderly Population in Urban Samayapuram, Trichy, Tamil Nadu, India
}

\author{
S. Pradeepa*, Heshweaanth, Dhanasowmiya and Elakkiyaraj
}

Department of Community Medicine, Chennai Medical College Hospital and Research Centre, Trichy, Tamil Nadu, India

*Corresponding author

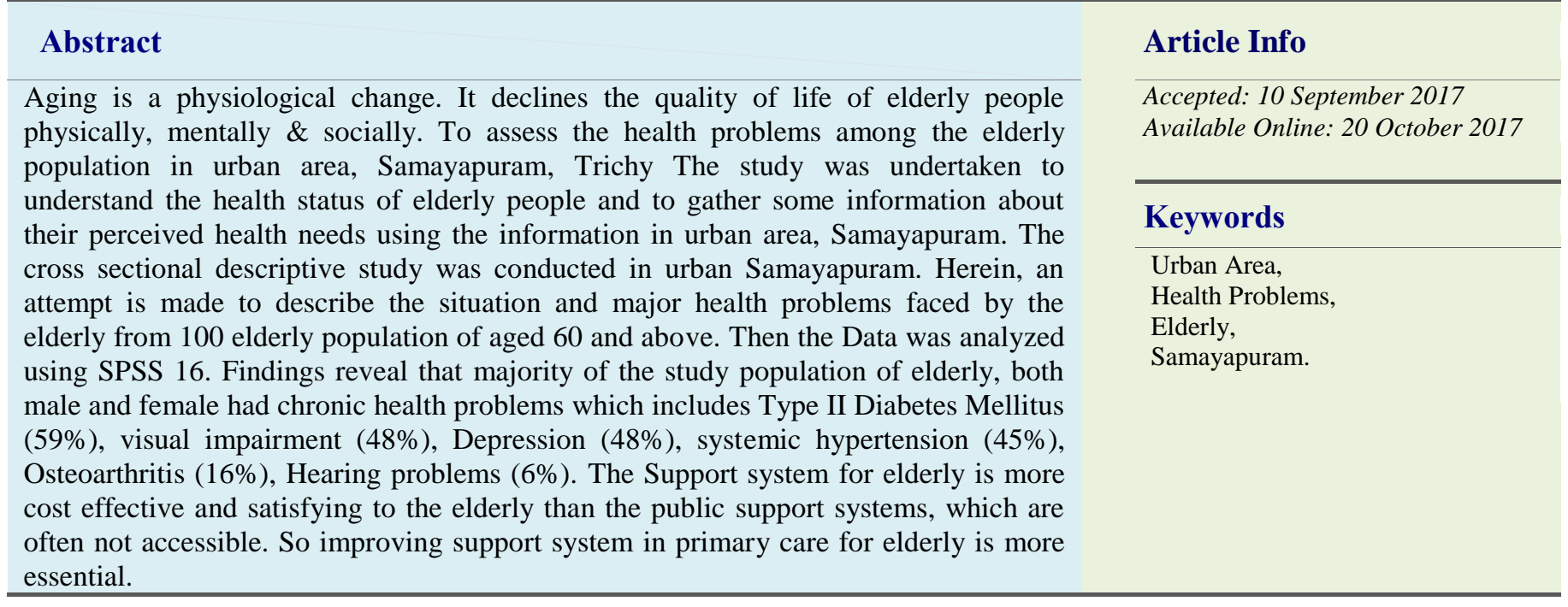

\section{Introduction}

The health of an individual does have a direct relationship with human resources development and economic development of a nation. One of the biggest social changes brought about by improved standards of living is population aging. ${ }^{12}$. Worldwide increase in longevity has shifted the age distribution toward older populations. Globally the number of elder above 60 years will nearly triple increasing from 606 million in 2000 to1.9 billion by $2050^{11}$. By 2050 , older people will outnumber children under the age of 14 Years. Health in old age is associated with health in earlier years of life, from womb to tomb. Intrauterine growth retardation may increases the risk of diseases of the cardiovascular system and diabetes in later life and also obese children have the risk of developing chronic diseases like diabetes, cancer, hypertension, respiratory disorders right up to old age ${ }^{8}$.

India is in a phase of demographic transition. There has been sharp increase in number of elderly person between $1991 \& 2001$ and it has been projected by the year 2050, the number of elderly would rise to about 324 million.

The demographic transition is attributed to the decreasing fertility and mortality rates due to availability of better health care services ${ }^{14}$. 
The common health problems of cardiovascular, neurological and musculoskeletal systems, cataract, hearing difficulties etc. are known to impair the quality of life in elderly population. Moreover, problems become more complicated when their children start neglecting them, elderly face psycho-social problem coupled with economic and health problem. They need to be helped to maintain their health and independent of life where possible ${ }^{4}$. Frequent cross sectional study among geriatric population can give an estimate of the future challenges facing geriatric medicine ${ }^{6}$.

\section{Materials and Methods}

The Cross sectional descriptive study was conducted in the urban health centre, Samayapuram, Trichy. All elderly patients above age of 60 years attending OPD of Urban Health Centre, Samayapuram were taken as study population.

A structured questionnaire was prepared to understand the health problems among elderly people including socio demographic profile of subjects. A total of 100 patients attending OPD on selected date fulfilling inclusion criteria and giving consent to participate in study were interviewed. The data was entered in M.S. Excel spread sheet and analyzed using SPSS 16version.

\section{Results and Discussion}

A study was conducted in the urban health centre, Samayapuram. A total of 100 patients attending OPD on selected date Fulfilling inclusion criteria were participated in this study. Table 1 shows the socio demographic distribution of study population, $81 \%$ were under $60-69$ years and mean age of study population was 66 years. $55 \%$ were males.

Maximum were Hindus 94\%, majority have completed primary school $48 \%$, unskilled workers $45 \%, 28 \%$ were unemployed, classified according to Kuppusamy classification. Marital status, $79 \%$ were married. Table 2 describes the Healthproblems among study population. In that majority of population have type II diabetes mellitus and hypertension. Among 59\% diabetic, 4\% had diabetic ulcer, $6 \%$ had diabetic neuropathy. Among $45 \%$ hypertension, $2 \%$ had hemorrhagic stroke. Most of the people visit the health care facility weekly $49 \%$. Among the study population $35 \%$ were alcoholic, $50 \%$ were tobacco users, $70 \%$ ophthalmology problems, mental stress 58\%.On general examination, among study population shows that $20 \%$ had pallor, $8 \%$ had pedal edema, $15 \%$ had cataract, $4 \%$ had right sided Hard of Hearing, $2 \%$ had left sided, $5 \%$ had bilateral. $2 \%$ had right pterygium, $3 \%$ had left pterygium.in this study.

In the present study, the age distribution of elderly between 60-69 years of age constituted the maximum of $81 \%$, followed by more than 70 years about $19 \%$. Number of females $45 \%$ was less than males $55 \%$ in our study as compared to more number of elderly males ${ }^{4}$. The main health problem in this study population was Diabetes mellitus about 59\%, Hypertension 45\%, Hearing problem 6\%, Osteoarthritis 16\%, Depression $48 \%$.

Diabetes and hypertension was marginally higher compared to other studies in other parts of urban area. A majority of elderly reported Poor eye sight $48 \%$, as compared with in present study was less about $6 \%^{8}$. Regarding education in the present study was only $34 \%$ were Illiterate; literacy has a positive impact on overall health.

The percentage of Loneliness as the reason for mental stress was $7 \%$ in present study as compared to $4.43 \%{ }^{14}$. Most of the study population was chronically sick compared to other study ${ }^{9}$. Alcohol and tobacco consumption in the present study not much higher than in other study ${ }^{4}$. With regard to the performance of day-today activities in the present study population was $44 \%$ of elderly were doing their daily work with some difficulties, $40 \%$ were doing their work without difficulties compared with study ${ }^{11}$ (1991) $44 \%$ had difficulty in performing physical activity.

The magnitude of marital status effects on disability and mortality, among elderly males and females ${ }^{7}$. Community based health insurance (CBHI) provides a viable alternative where the government services cannot reach the elderly ${ }^{8}$. Implementation of proper and cost effective programmes for the elderly in rural India is imperative ${ }^{2}$ Recommendation under the UHC framework have prioritized primary and secondary prevention and health promotion among the age and avoiding institutionalization ${ }^{5}$.

Recommendations include establishing collaborative agreements with ophthalmological services to provide high quality IOL surgery to these patients, training of health staff to identify and refer patients in need of surgery, monitoring the uptake of cataract surgery among patients needing services, and monitoring the outcome of surgery to improve refractive outcome ${ }^{3}$. 
Table.1 Socio demographic distribution of study population

\begin{tabular}{|l|l|l|}
\hline & FREQUENCY & PERCENTAGE \\
\hline AGE IN YEARS & & \\
$60-69$ & 81 & $81 \%$ \\
$>70$ & 19 & $19 \%$ \\
GENDER & 55 & \\
Male & 45 & $55 \%$ \\
Female & & $45 \%$ \\
& & \\
MARITAL STATUS & 79 & $79 \%$ \\
Married & 1 & $1 \%$ \\
Unmarried & 20 & $20 \%$ \\
Widow & & \\
& 34 & $34 \%$ \\
EDUCATION & 48 & $48 \%$ \\
Illiterate & 18 & $27 \%$ \\
Primary school & 0 & 0 \\
Middle school & 0 & 0 \\
High school & 0 & 0 \\
Diploma & 0 & 0 \\
Graduate & & \\
Professional & & $28 \%$ \\
OCCUPATION & 28 & $45 \%$ \\
Unemployed & 45 & $27 \%$ \\
Unskilled & 27 & 0 \\
Semiskilled & 0 & 0 \\
Skilled work & 0 & 0 \\
Clerk & 0 & 0 \\
Semi profession & 0 & \\
Profession & \multicolumn{2}{|l}{} \\
\hline & &
\end{tabular}

Table.2 Health problems among study population

\begin{tabular}{|l|l|l|}
\hline & FREQUENCY & PERCENTAGE \\
\hline DISEASE & & \\
Type 2 DM & 59 & $59 \%$ \\
Systemic HTN & 45 & $45 \%$ \\
Hearing problems & 6 & $6 \%$ \\
Vision problem & 6 & $6 \%$ \\
Arthritis & 16 & $16 \%$ \\
URI/FEVER & 2 & 2 \\
& & \\
& & \\
DIESEASE DURATION & & \\
Acute & 21 & $21 \%$ \\
Chronic & 79 & $79 \%$ \\
& & \\
HEALTHCARE VISIT & 23 & $23 \%$ \\
Monthly & 16 & $16 \%$ \\
Occasionally & 12 & $12 \%$ \\
Rarely & 49 & $49 \%$ \\
Weekly & & \\
ALCOHOL CONSUMPTION & 8 & $8 \%$ \\
Everyday & 3 & $3 \%$ \\
Ocassionally & 20 & $20 \%$ \\
Weekly & 4 & $4 \%$ \\
Rarely & 65 & \\
\hline
\end{tabular}




\begin{tabular}{|c|c|c|}
\hline \multicolumn{2}{|c|}{$65 \%$} & $65 \%$ \\
\hline \multicolumn{3}{|l|}{ TOBACCO USAGE } \\
\hline Everyday & 28 & $28 \%$ \\
\hline Occasionally & 22 & $22 \%$ \\
\hline No & 50 & $50 \%$ \\
\hline \multicolumn{3}{|l|}{ EYE PROBLEMS } \\
\hline Cataract & 15 & $15 \%$ \\
\hline Refractive error & 15 & $15 \%$ \\
\hline Nil & 70 & $70 \%$ \\
\hline \multicolumn{3}{|l|}{ DISEASE COMPLICATION } \\
\hline \multirow[t]{2}{*}{ Type II DM } & 4 & $4 \%$ \\
\hline & 6 & $6 \%$ \\
\hline SHTN & 2 & $2 \%$ \\
\hline Infarction & 4 & $4 \%$ \\
\hline \multicolumn{3}{|l|}{ MENTAL STRESS } \\
\hline No & 42 & $42 \%$ \\
\hline \multirow[t]{2}{*}{ Yes } & 28 & $28 \%$ \\
\hline & 7 & $7 \%$ \\
\hline Poverty & 23 & $23 \%$ \\
\hline
\end{tabular}

One of the major elements of health status of elderly is perceived health and early surveillance of the health needs, is required to provide cost effective services. The Support system for elderly is more cost effective and satisfying to the elderly than the public support systems, which are often not accessible. So improving support system in primary care for elderly is more essential.

\section{References}

1. Acharya A, Ranson K. Health care financing for the poor: Community-based health insurance schemes in Gujarat. Economic and Political Weekly. 2005; 40: 4, 141-4, 150.

2. Alam M. Ageing in India: A country profile. Bold. 2000; 10(3): 5-22.

3. Angra SK, Murthy GVS, Gupta SK, Angra V. Cataract related blindness in India and its social implications. Indian Journal of Medical Research. 1997; 106: 312-324.

4. Balamurugan.J -Health problems of aged peopleIJRSS [AUG 2012].

5. Chen C. Widows in India: Social Neglect and Public Action. New Delhi: Sage; 1998.

6. Eduardo Hernandez- Vila -JNC 8 hypertensive classification.
7. Goldman N, Korenman S, Weinstein R. Marital status and health among the elderly. Social Science and Medicine. 1995; 40(12): 1, 717-1, 730.

8. Jharna Bag, Debasish Sanyal, Liza Thankam Daniel -Development and validation of perceived health problem questionnaire for elderly population; www.iosrjournals.org.

9. Kaur et al., - Evaluation of health and social problems among elderly at rural area in Indore District.

10. Kuppasamy B. Manual of socioeconomic status (urban) Manasayan, Delhi, 1981.

11. Nair. -Prevalence of morbidity among elderly [IJCM- 2015].

12. Pranay Gandhi, Sunita Sharma, Prateek Gandhi A cross-sectional study of common health problems of the elderly. [Indian journal of applied research - may 2014].

13. Socioeconomic status. The American Hertiage ${ }^{R}$ New Dictionary of Cultural Literacy, Third edition. Available from http://www.dictionary.com/browse/socioeconomi cstatus. Accessed on $14^{\text {th }}$ October 2016

14. Thakur R.P., A Banerjee and VB Nikumb. Annals of medical and health sciences research [Medknow publication].

\section{How to cite this article:}

Pradeepa S., Heshweaanth, Dhanasowmiya and Elakkiyaraj. 2017. Health Problems among Elderly Population in Urban Samayapuram, Trichy, Tamil Nadu. Int.J.Curr.Res.Aca.Rev. 5(10), 58-61. doi: https://doi.org/10.20546/ijcrar.2017.510.009 